\title{
Maxillofacial Radiology 178
}

SADJ March 2020, Vol. 75 No. 2 p100

\section{CJ Nortjé}

Below are a clinical picture and several radiographic images of a pathological lesion that may present in the maxillofacial region of a patient. Discuss the radiographic features and what is your diagnosis?

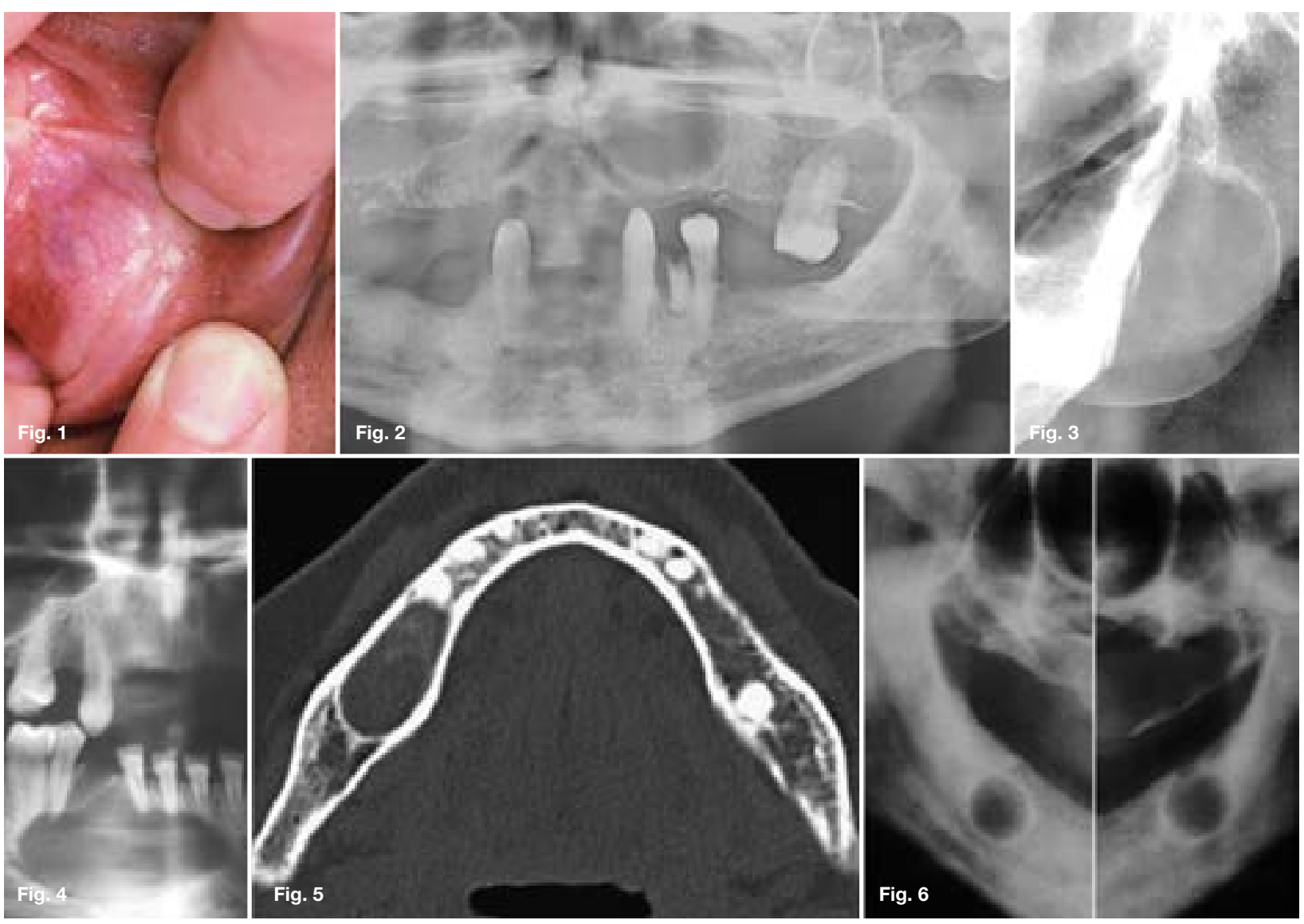

\section{INTERPRETATION}

The classic radiological appearance of the above lesions is that they are round or ovoid radiolucencies surrounded by a narrow radiopaque margin. A histological diagnosis of residual radicular cyst was made. These cysts are those that are retained after removal of the offending non-vital tooth. There have been a relatively few publications on the subject although it has been estimated that that they present $10 \%$ of all odontogenic cysts. Figure 6 illustrates two residual radicular cysts on a SS White Panorex taken forty years ago. The histopathological features of the residual cyst are similar to those described for conventional radicular cysts. However, because the cause of the cyst has been removed, residual cysts may progressively become less inflamed so that eventually the cyst wall is composed of uninflamed collagenous fibrous tissue. The epithelial lining may be thin and regular and indistinguishable from a developmental cyst or lateral periodontal cyst. In these cases it is important to establish the relationship of the lesion to the teeth involved.

Christoffel J Nortjé: $B C h D, P h D, A B O M R, D S c$. Faculty of Dentistry, University of the Western Cape.

ORCID Number: 0000-0002-9717-5514

Email: cnortje@uwc.ac.za
A few well documented cases have been reported which indicate that squamous carcinoma may occasionally arise from the epithelial lining of radicular and residual radicular cysts. Any number of odontogenic and nonodontogenic cysts and tumours can mimic the appearance of a residual radicular cyst. Calcifications of various kinds are frequently present and are a particular feature of residual radicular cysts that have been present for a long time. These lesions should be excised surgically, even in the absence of symptoms. The residual cysts do not recur after appropriate management, however intraosseous fibrous scars are possible, especially when both cortical plates have been lost; this can give the appearance of a persistent radiolucent lesion. Finally a number of pathologists (Bhaskar, 1972) concluded that the majority of radicular cysts undergo resolution following root canal therapy and do not require surgical intervention.

\section{Reference}

1. Shear M, \& P Speight: Cysts of the Oral and Maxillofacial Regions $4^{\text {th }}$ Edition, Blackwell, and Munksgaard 2007.

2. Bhaskar S. N Nonsurgical resolution of radicular cysts. Oral Surgery, Oral Medicine, Oral Pathology 34, 1972, 458-68. 